\title{
Pulmonary echinococcosis mimicking multipl lung metastasis of breast cancer: The role of fluoro-deoxy-glucose positron emission tomography
}

\author{
Yavuz Kurt*1, Qlker Sücüllü ${ }^{1}$, Ali Qlker Filiz' ${ }^{1}$, Muammer Urhan ${ }^{2}$ and \\ Mehmet Levhi AkRn ${ }^{1}$
}

Address: ${ }^{1}$ Department of General Surgery, GATA Haydarpasa Istanbul, Turkey and ${ }^{2}$ Department of Nuclear Medicine, GATA Haydarapasa Istanbul, Turkey

Email: Yavuz Kurt* - drykurt@yahoo.com; Qlker Sücüllü - ilkersucullu@yahoo.com; Ali Qlker Filiz - aliilker@yahoo.com;

Muammer Urhan - muammerurhan@yahoo.com; Mehmet Levhi AkRn - ak1nm@yahoo.com

* Corresponding author

Published: 21 January 2008

World Journal of Surgical Oncology 2008, 6:7 doi:10.1/86/1477-7819-6-7

This article is available from: http://www.wjso.com/content/6/l/7

(C) 2008 Kurt et al; licensee BioMed Central Ltd.

This is an Open Access article distributed under the terms of the Creative Commons Attribution License (http://creativecommons.org/licenses/by/2.0), which permits unrestricted use, distribution, and reproduction in any medium, provided the original work is properly cited.
Received: 15 January 2007

Accepted: 21 January 2008

\begin{abstract}
Background: Echinococcosis is still a serious problem particularly in endemic areas such as South and Central America, Mediterranean countries, and Russia. Furthermore, hydatid cysts of the lung are often indistinguishable from a variety of other pulmonary lesions such as lung tumors

Case presentation: We herein present a 56 year old woman with breast cancer who presented with bilateral pulmonary nodules due to echinococcosis granulosis that mimicked metastatic breast cancer to the lung.

Conclusion: During the evaluation of the malignancies which could metastasize to the lung, it must be kept in mind that the appearance of bilateral multiple pulmonary masses can also be the sign of a pulmonary echinococcosis especially in endemic areas. FDG-PET with its known high negative predictive value in characterizing indeterminate pulmonary nodules $>I \mathrm{~cm}$ is very helpful to characterize this kind of lesions.
\end{abstract}

\section{Background}

Echinococcosis is a parasitic infestation caused by larvae of the tapeworm echinococcus. Although there are four species the vast majority of hydatid disease in humans are caused by echinococcus granulosis which causes cystic echinococcosis and has a worldwide distribution. Echinococcus multilocularis causes alveolar echinococcosis which can be seen less frequently in humans. In cystic echinococcosis humans are an aberrant host and are usually infected by oral ingestion of excrement from an infected dog. Infected red fox has an important role for alveolar echinococcosis $[1,2]$. Parasitic eggs turned to lar- vae form after ingestion in the intestine and migrate to the other organs by penetrating intestinal wall and then develop cystic or alveolar echinococcosis. The liver and lungs are the most common involved organs. Hydatid cysts may rupture, can become secondarily infected, or may infect other organs. Alveolar echinococcosis behaves like a malignant tumor biologically. Humans Echinococcosis is still a serious problem particularly in endemic areas such as South and Central America, Mediterranean countries, Australia and Russia. Furthermore, hydatid cysts of the lung are often indistinguishable from a variety of other pulmonary lesions such as lung tumors [2-4]. 


\section{Case presentation}

A 56-year old woman admitted with a breast lump, chronic cough and chest pain. There was no medical or family history of note. On physical examination we discovered a palpable mass in the medial outer quadrant of the right breast and ipsilateral palpable axillary and supraclavicular lymph nodes. Mammography and ultrasound revealed a $2 \mathrm{~cm}$ nodule with irregular border including micro calcifications which was confirmed to be invasive ductal carcinoma by a fine needle biopsy. Chest radiography and computed tomography showed multiple nodules and masses involving both lungs highly suspicious to be metastatic in origin (Figure 1). Positron Emission Tomography (PET) scans showed increased Fluoro-deoxy-glucose (FDG) uptake in the breast cancer and axillar, supraclavicular lymph nodes as it's expected but there is no FDG uptake in pulmonary lesions suggesting a benign origin (Figure 2). She was coming from the east part of the country where hydatid disease is endemic. Positive indirect hemaglutination test supported the diagnosis of pulmonary echinococcosis. Chemotherapy for Stage IIIC breast cancer (Adriamycin, cyclophosphamid and paclitaxel) and albendazol treatment began for the patient.

\section{Discussion}

Hydatid disease is one of the most important helminthic diseases. Echinococcosis is worldwide in distribution; it occurs most commonly in sheep and cattle-raising areas [4]. Lung is the second most common involved organ but it is hard to distinguish pulmonary echinococcosis from a variety of other pulmonary lesions especially metastatic lesions to the lung. In women, the appearance of metasta-

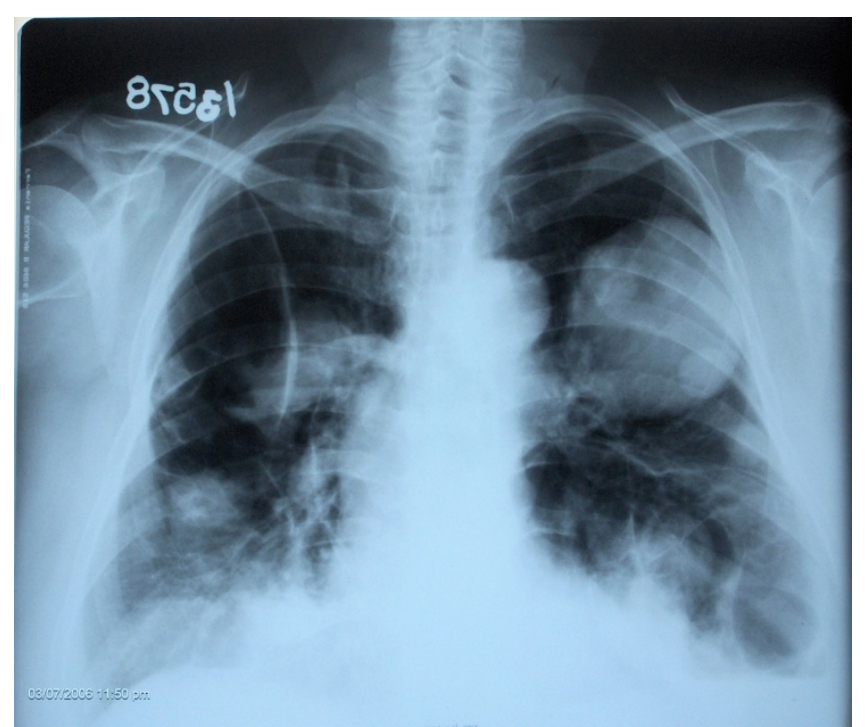

\section{Figure I}

Chest radiography shows multiple nodules and masses involving both lungs. sis is a frequent complication of breast cancer. The lung is the second most common organ for metastasis of breast cancer after the bone [5]. We present herein a patient with breast cancer who had also bilateral pulmonary multiple masses in different size and irregular shape which were determined by plain X-Ray and thorax CT thought to be metastasis to lung. Despite increased FDG uptake for breast cancer and metastatic lymph nodes, pulmonary nodules and masses had no FDG uptake so we excluded malignancy by FDG-PET scan and decided with a high degree of certainty that they were benign lesions. In fact there is a wide differential diagnosis for multiple nodules and masses with extensive pulmonary involvement on radiography or computed tomography, which includes pulmonary echinococcosis. But they are not as accurate as FDG PET to exclude the metastatic pulmonary lesions especially $>1 \mathrm{~cm}$. Needle biopsy or aspiration of the hydatid cysts since anaphylactic shock would not necessary develop when draining a pulmonary abscess or other cystic lesions rather than echinococcosis [2].

A study by Schirrmeister et al showed that whole body FDG PET is as accurate as panel of imaging modalities currently employed and significantly more accurate in detecting multifocal disease, lymph node involvement and distant metastasis [6]. FDG PET has been shown to have impact on the staging and management of recurrent or metastatic breast cancer in cases of suspicion and in a follow-up setting. The current oncological situation can be clarified with a single basic imaging modality $[6,7]$.

There is no doubt that multiple pulmonary nodules may be commonly seen in patients with inflammatory diseases such as echinococcosis but we want to emphasize in this manuscript that it is hard to differentiate whether these nodules are malign or not especially in patients with malignancy. At this point FDG Pet scan can be helpful by showing the high metabolic activity of the nodules. Even though Stumpe et al [1] found that in patients with alveolar echinococcosis baseline PET scans showed multifocally increased FDG uptake in the hepatic lesions' periphery, liver lesions were FDG negative in patients with cystic echinococcosis.

\section{Conclusion}

FDG-PET besides being a strong indicator of malignant lung nodules, is a reliable diagnostic test that can avert needle biopsy of lesions that do not show significant metabolic activity. During the evaluation of the malignancies which could metastasize to the lung, it must be kept in mind that the appearance of bilateral multiple pulmonary masses can also be the sign of a pulmonary echinococcosis especially in endemic areas. FDG-PET with its known high negative predictive value in characterizing indetermi- 


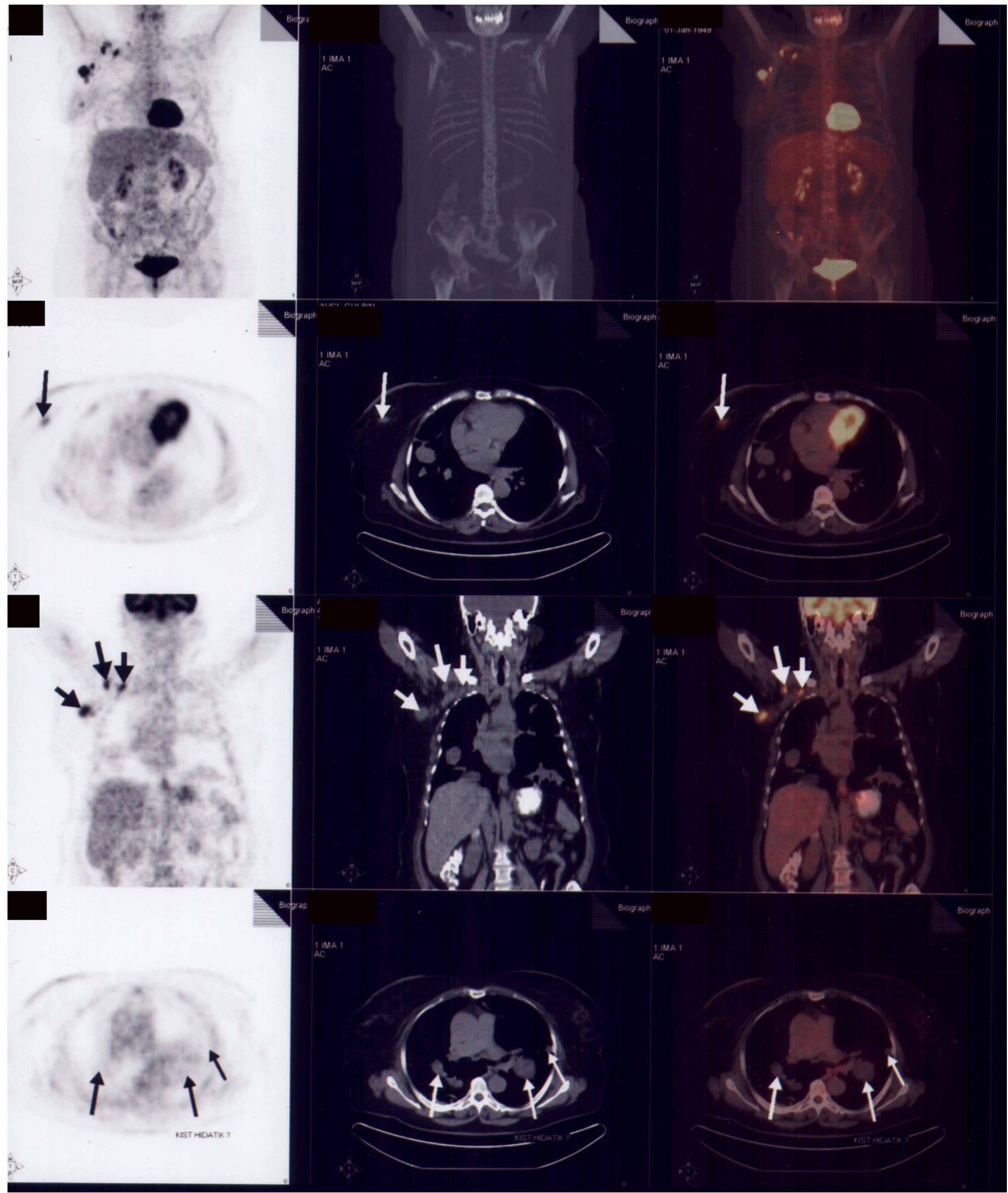

Figure 2

FDG PET scans, First Column of the Figure showed increased FDG uptake in both breast cancer and in metastatic axillary and supraclavicular lymph nodes (arrows) and also no FDG Uptake of the benign pulmonary lesions (small arrows). 
nate pulmonary nodules $>1 \mathrm{~cm}$ is very helpful to characterize this kind of lesions

\section{Competing interests}

The author(s) declare that they have no competing interests.

\section{Authors' contributions}

YK drafted the manuscript, ÝS helped in preparing the manuscript, AÝF did literature search and helped with manuscript, MU helped with the nuclear medicine component of manuscript, MLA helped with preperation of manuscript.

All authors read and approved the final manuscript.

\section{Acknowledgements}

Written informed consent was obtained from the patient for publication of this case report

\section{References}

I. Stumpe KD, Renner-Schneiter EC, Kuenzle AK, Grimm F, Kadry Z, Clavien PA, Deplazes P, von Schulthess GK, Muellhaupt B, Ammann RW, Renner EL: F-I8-fluorodeoxyglucose (FDG) positronemission tomography of Echinococcus multilocularis liver lesions: prospective evaluation of its value for diagnosis and follow-up during benzimidazole therapy. Infection 2007, 35: II-18.

2. Morar R, Feldman C: Pulmonary echinococcosis. Eur Respir J 2003, 2 I: I 069-1077.

3. Erdogan A, Ayten A, Demircan A: Methods of surgical therapy in pulmonary hydatid disease: is capitonnage advantageous? ANZ J Surg 2005, 75(I I):992-6.

4. Gencer M, Ceylan E: Pulmonary echinococcosis with multiple nodules mimicking metastatic lung tumor in chest radiography. Respiration in press. 2006 Jan 23

5. Bland KI, Vezeridis MP, Copeland EM: Breast. In Principles of Surgery 7th edition. Edited by: Schwartz SI. New York, PA: McGraw-Hill; 1999:558-9.

6. Schirrmeister H, Kuhn T, Guhlmann A, Santjohanser C, Horster T, Nussle K, Koretz K, Glatting G, Rieber A, Kreienberg R, Buck AC, Reske SN: Fluorine-I 8 2-deoxy-2-fluoro-D-glucose PET in the preoperative staging of breast cancer: comparison with the standard staging procedures. Eur I Nucl Med 200I, 28:35I-358.

7. Siggelkow W, Zimny M, Faridi A, Petzold K, Buell U, Rath W: The value of positron emission tomography in the follow-up for breast cancer. Anticancer Res 2003, 23:1859-1867.
Publish with Bio Med Central and every scientist can read your work free of charge

"BioMed Central will be the most significant development for disseminating the results of biomedical research in our lifetime. "

Sir Paul Nurse, Cancer Research UK

Your research papers will be:

- available free of charge to the entire biomedical community

- peer reviewed and published immediately upon acceptance

- cited in PubMed and archived on PubMed Central

- yours - you keep the copyright
BioMedcentral 